\title{
Magnetic Susceptibility in the Soils Along Communication Routes in the Town of Opole
}

\author{
Katarzyna Łuczak*, Grzegorz Kusza' \\ 1 Institute of Environmental Protection and Development, University of Opole, Oleska 22, 45-052 Opole, \\ Poland \\ * Corresponding author's e-mail: kluczak@uni.opole.pl
}

\begin{abstract}
Magnetic susceptibility measurements were taken in eight selected streets of Opole, with diversified vehicle traffic intensity. The experiment surfaces were marked on every street, with two separate zones: A - a strip directly adjacent to the road and B - a strip $1 \mathrm{~m}$ away from the road edge. The carried out research indicated considerable influence of communication-generated pollution, with simultaneous influence of other local emission sources. The relation of magnetic anomalies was indicated, which may be the result of ferromagnetic materials aggregation, originating mainly from combustion processes. The road structure, including the surface condition, the main construction material and susceptibility of the surface to cracking are equally important when considering the magnetic increase. A considerable variation of magnetic measurements in different season was pointed out; however, the largest median values of magnetic susceptibility were recorded in the summer season.
\end{abstract}

Keywords: urban soils, magnetic susceptibility, traffic pollution

\section{INTRODUCTION}

The number of vehicles on Polish roads has been growing dynamically over the recent years. The visible consequence of the increasing transport and communication intensity is the pollution of soil with heavy metals or polycyclic aromatic hydrocarbons. Communication pollution is mainly generated through fuel combustion in engines, tyres and brake pads wear as well as vehicles construction parts damage [Hunt et al. 1983; Hoffmman et al. 1999; Bućko et al. 2010; Wawer et al. 2015a]. This problem can be noticed particularly in urban areas and city centres, where the vehicular traffic is very heavy. The pollution which infiltrates into soil, including heavy metals (lead, copper, zinc and cadmium, in particular) may disturb homeostasis, particularly in the urban areas [Czerniak, 2004]. Integrated monitoring studies, based on chemical and biological parameters monitoring as well as magnetic characteristics have been carried out for several years, in order to determine the degree of chang- es and transformation of the soil environment [Schmidt, 2005; Strzyszcz et al. 2006].

Contemporary environment monitoring studies are based on the most effective methods, which allow for obtaining the current environment condition as fast as possible. Magnetic susceptibility measurements, which are one of such methods, enable to determine the threat to soils from immissions (depositions) of ferromagnetic elements [Strzyszcz and Magiera, 2003; Magiera et al. 2011]. Magnetic susceptibility is an easily measured geophysical data, which describes the ability of a substance to change its magnetisation level under the influence of an external magnetic field [Evans and Heller, 2003; Strzyszcz and Magiera, 1998]. Beckwith et al. (1986) demonstrated the linear relation between the content of magnetic particles and copper, iron, lead and zinc in the dust of anthropogenic origin. The magnetic susceptibility values are much higher compared to the natural values in polluted areas. It is assumed that non-polluted soils have natural magnetic susceptibility on the level below $30 \times 10^{-5}$ 
SI units [Strzyszcz et al. 1994]. If this value is exceeded, then the content of anthropogenic ferromagnetic materials is increased. Additionally, natural factors, such as the source rock type or physical and chemical processes in soil influence the magnetic susceptibility values [Maher et al. 2003; Magiera et al. 2011].

The use of field magnetometry, based on the measurements of magnetic susceptibility of upper soil layer in situ, should be used in determining the areas with potential risk of heavy metals contamination of soil, as well as in soils monitoring due to its simplicity, accuracy and quick measurement procedure [Dearing, 1999; Magiera, 2004, Strzyszcz et al. 2006]. The correct interpretation of the obtained magnetic susceptibility values from the upper soil layer enables to estimate the size and range of pollution deposition, as well as the present magnetic particles and the related heavy metals. The application of this method in soils monitoring allows to reduce costs by limiting the number of expensive analyses of heavy metal content in soils only to the locations with detected magnetic anomalies (Lukasik et al. 2013; Schmidt et al. 2005).

The aim of the carried out research was to determine the possibility of applying magnetic susceptibility measurements for the analysis of the pollution degree and scope of the soils located along the communication routes in the urbanised areas of Opole (south-western Poland).

\section{MATERIALS AND METHODS}

Eight permanent experiment areas were set up in September 2016, located along the main communication routes of Opole. Each sampling site was divided into two zones $\mathrm{A}$ and $\mathrm{B}, 1 \mathrm{~m}$ wide and $10 \mathrm{~m}$ long; zone $\mathrm{A}$ was adjacent directly to the road edge and zone B was located from 1 to $2 \mathrm{~m}$ from the road edge. All zones were divided into 10 permanent squares, sized $1 \times 1 \mathrm{~m}$, in which during the period from September 2016 to October 2017 measurements of magnetic susceptibility were taken once a month.

The MS equipment by the British Bartington company was used during the measurements of magnetic susceptibility of soils. The measurements were taken with the MS2 measuring device and MS2D sensor, operating at $0.958 \mathrm{kHz}$ frequency [Bartington Instruments Ltd. 1999]. The measurement depth of $0-10 \mathrm{~cm}$ under the soil sur- face is related to the MS2D sensor construction [Dearing, 1999]. The measurements were taken having previously removed minor vegetation, in order to obtain the correct, full contact of the measuring tool sensor with the soil surface.

The selected experiment sites had various average traffic intensity during a day, from 7062 (no. 1 - Oleska) to 22566 (no. 8 - Wroclawska) vehicles, moving with average speed of $50 \mathrm{~km} / \mathrm{h}$ (Tab. 1).

The obtained results were statistically processed, using Statistica 13.1 software [O Dell Statistica 2016].

\section{RESULTS AND DISCUSSION}

The magnetic susceptibility studies carried out (in situ) on the soils along the main streets of Opole demonstrated the exceeded value of $30 \times 10^{-5} \mathrm{SI}$, which is approved in literature as the threshold value, above which anthropopressure influence is considerable. The magnetic susceptibility values below the above-mentioned threshold value are characteristic for the natural increase in magnetic minerals. Figures 1 and 2 present the monthly distribution of the measured magnetic susceptibility values. The magnetic susceptibility measurements taken in the zone directly adjacent to the road edge (zone A) demonstrate an increase of magnetic field, i.e. relatively large content of ferromagnetic elements. Medians in zone A were within the range $110-149 \times 10^{-5} \mathrm{SI}$, with the maximum value measured in the sites no. 1 (ul. Marka z Jemielnicy) in winter (December) equal to $338 \times 10^{-5}$ SI (Fig. 1).

In the zone $1 \mathrm{~m}$ away from the road edge (zone B), magnetic susceptibility value was nearly halved, where median was in the range from

Table. 1. Values of the average traffic intensity on selected streets of Opole

\begin{tabular}{|c|c|c|}
\hline No. & Street name & $\begin{array}{c}\text { Values of the average } \\
\text { traffic during a day } \\
(2016-2017)\end{array}$ \\
\hline 1 & Marka z Jemielnicy & 7833 \\
\hline 2 & Plebiscytowa & 10526 \\
\hline 3 & Horoszkiewicza & 11380 \\
\hline 4 & Oleska & 7062 \\
\hline 5 & Wroclawska & 21498 \\
\hline 6 & Proszkowska & 13537 \\
\hline 7 & Niemodlinska & 10524 \\
\hline 8 & Wroclawska & 22566 \\
\hline
\end{tabular}




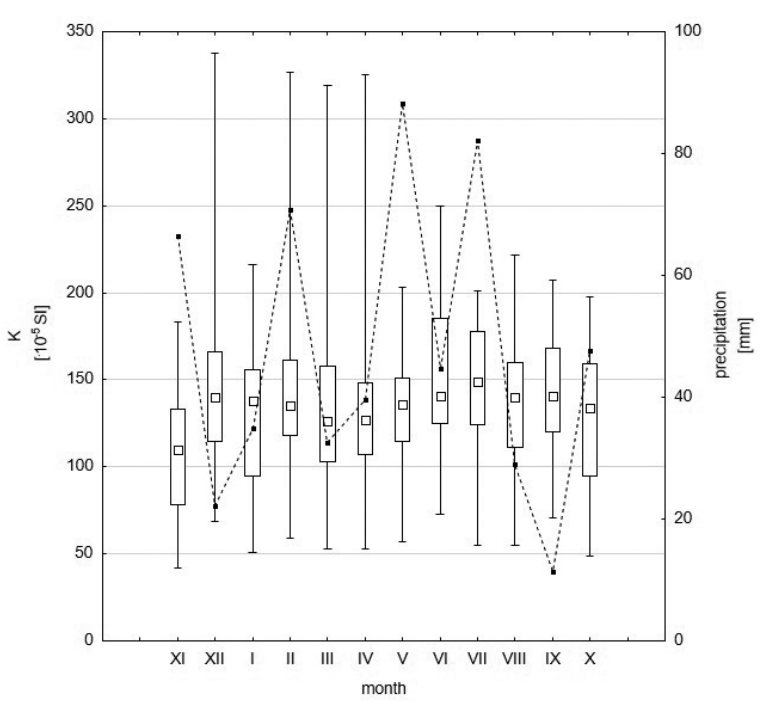

Fig. 1. Distribution of monthly measurements of magnetic susceptibility for zone A

57 to $76 \times 10^{-5} \mathrm{SI}$, and the maximum values measured in the sampling sites no. 8 (ul. Wroclawska) of $145 \times 10^{-5}$ SI (Fig. 2). The difference may be caused by the quality of the asphalt material used in the road surface and the amount of magnetic minerals content (basalt mass). Due to the cracking of the road surface, the material is transferred to the adjacent surfaces, which causes an increase of magnetic field.

The research carried out by Wawer et al. (2015) demonstrated a considerable gathering of ferromagnetic elements in the soils adjacent to the road with heavily cracked surface, as compared to the roads with undamaged surfaces. Moreover, higher values of the measured parameter may be caused by the deposition of communication pollution, including the emission of the soot from exhaust systems, particles from the worn metal
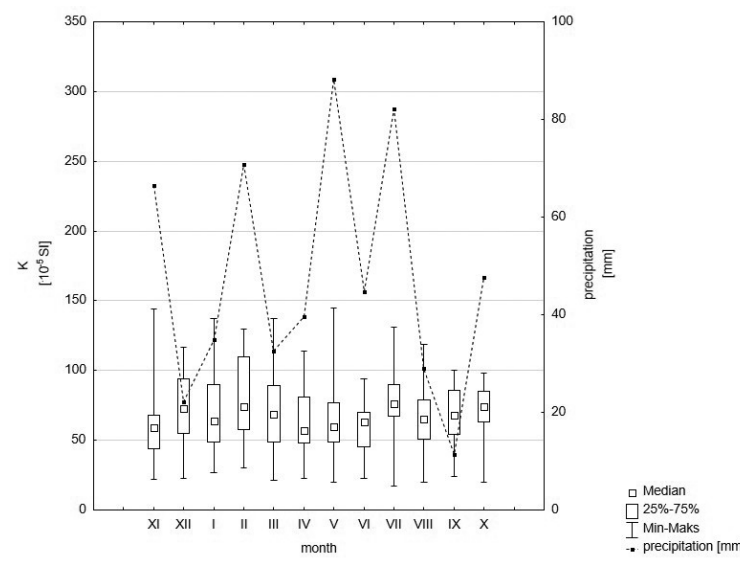

Fig. 2. Distribution of monthly measurements of magnetic susceptibility for zone B parts, brakes, tyres as well as magnetic particles from metal elements corrosion and lacquer coating (Czerniak i Poszyler-Adamska 2009). That is why the studies monitoring the condition of road environment require more caution, as there are many variables, which influence the analysed parameters. The tests of magnetic susceptibility of the soil should be carried out away from the road edge (min. $1 \mathrm{~m}$ ), in this way eliminating the influence of the road construction material, which can disturb the obtained measurement values and their correct interpretation.

Taking into consideration the whole study period, the magnetic susceptibility measured in zone A showed great variability. Considerable distribution of the obtained values, in the surface no. 1 , in particular, may be the result of many variables which influence the value of the analysed parameter. The influence of anthropogenic factors, such as the vicinity of a railway line or emission of pollution from the former "Bolko" cement plant, has to be considered. The studies carried out by Gołuchowska et al. $(2010,2012)$ indicate the problem of dust depositions in the cement plant influence zone, with excessive amounts of chromium, cadmium or zinc, among others. The relations between the intensity of magnetic susceptibility and the content of heavy metals discussed in literature, are one of the reasons for increasing magnetic susceptibility and, in this way, the increase of magnetic susceptibility of roadside soils [Hunt et al. 1984; Strzyszcz and Magiera 1998; Schmidt et al. 2005; Rachwał et al. 2017].

Referring to the distribution of the values of the magnetic parameter, more than $70 \%$ of measurements in zone A were within the range from 100 to $180 \times 10^{-5} \mathrm{SI}$, which indicates high homogeneity of the measurements (Fig. 3). A similar tendency of the measurements was obtained in zone B. Disregarding the extreme values - maximum and minimum - more than $70 \%$ of the measurements were within the range $40-100 \times 10^{-5} \mathrm{SI}$ (Fig.4). This confirms the usefulness of the magnetic susceptibility measurement method in environment studies.

Defining the changes resulting from weather conditions, which are different in winter, spring, summer and fall, was an important aspect discussed in the article. Maher (1998) and Maher et al. (2003) determined the relation between the magnetic susceptibility of the surface soil layer and air temperature and humidity, indicating the influence of climate factors on the processes of 


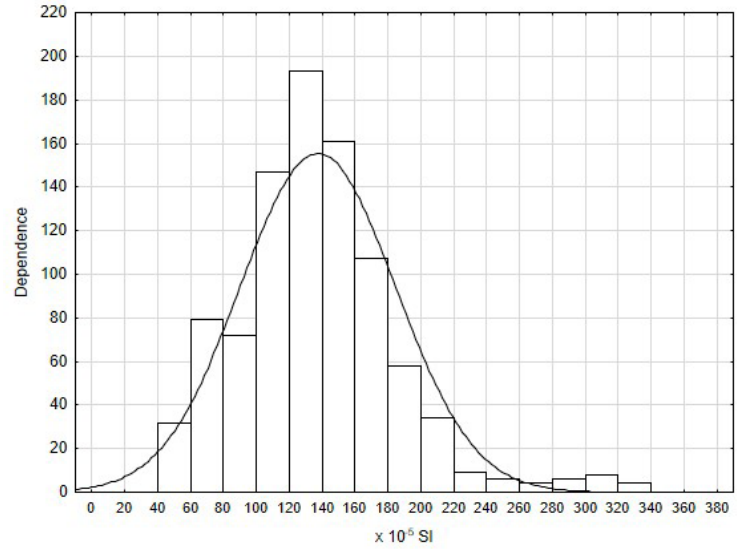

Fig. 3. Histogram of magnetic susceptibility measurements distribution in zone $\mathrm{A}$

pollution migration in soils. The results of magnetic tests obtained from soils in Opole, due to the fact that they were carried out during one year, do not allow to conclusively demonstrate the influence of precipitation and temperature on differentiation of magnetic susceptibility values.

The monthly measurements of magnetic susceptibility demonstrated seasonal rhythm of changes of the analysed parameter. The obtained values are grouped in three periods: winter, spring and summer-fall. The winter period was limited to December, which shows distinctly different results. This may be the result of the influence of other sources of ferromagnetic particles, e.g. low emission caused by heating flats with low quality fuel and partial combustion. During the spring period (from February to April), the measured magnetic susceptibility values were lower compared to the winter period. The last measurement season was in the period from May to October and its values were at a relatively high and stable level

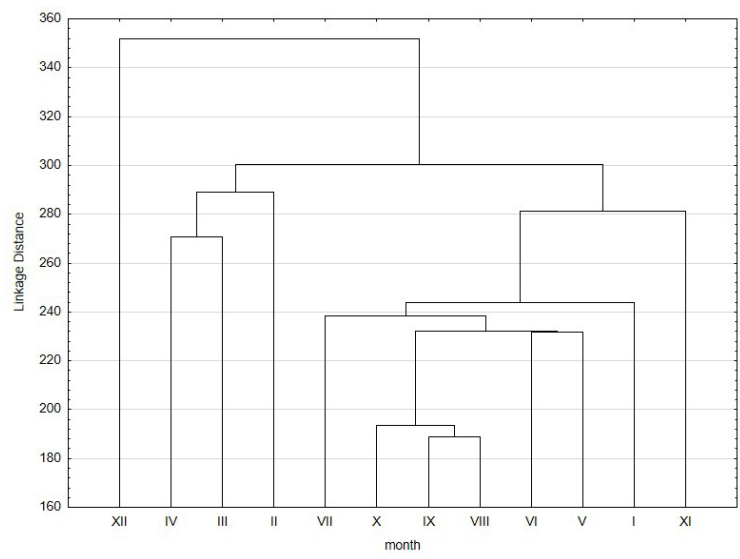

Fig. 5. Seasonal grouping of the obtained magnetic susceptibility values

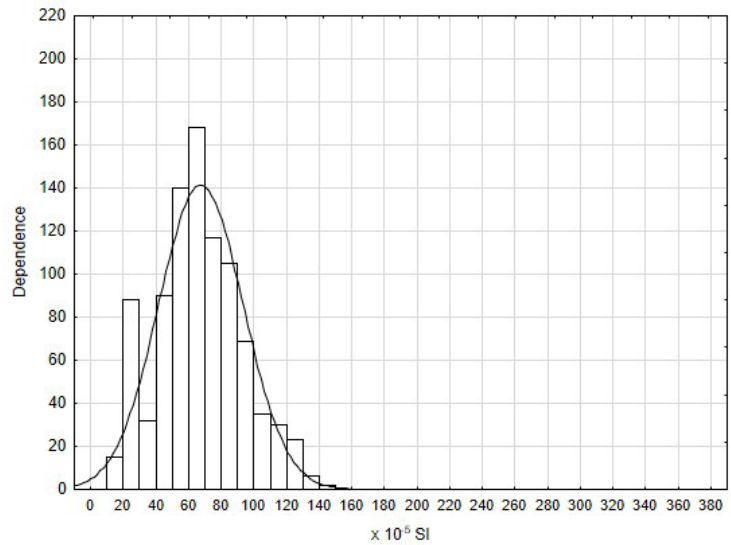

Fig. 4. Histogram of magnetic susceptibility measurements distribution in zone $\mathrm{B}$

(Fig. 5). The seasonal changes of magnetic susceptibility values of the surface soil layer may be of importance in environment monitoring; therefore, one should properly select the appropriate period of field test realisation.

The average traffic intensity as well as the speed of vehicles did not influence the measured magnetic susceptibility values. The highest values of magnetic susceptibility were determined in the areas of moderate traffic intensity (Fig.6).

\section{CONCLUSIONS}

1. The results of the carried out research indicate the increased magnetic susceptibility in the soils located along the selected communication routes, with a simultaneous tendency to decrease the magnetic susceptibility values, along with the distance from a road edge.

2 . The obtained magnetic measurements results

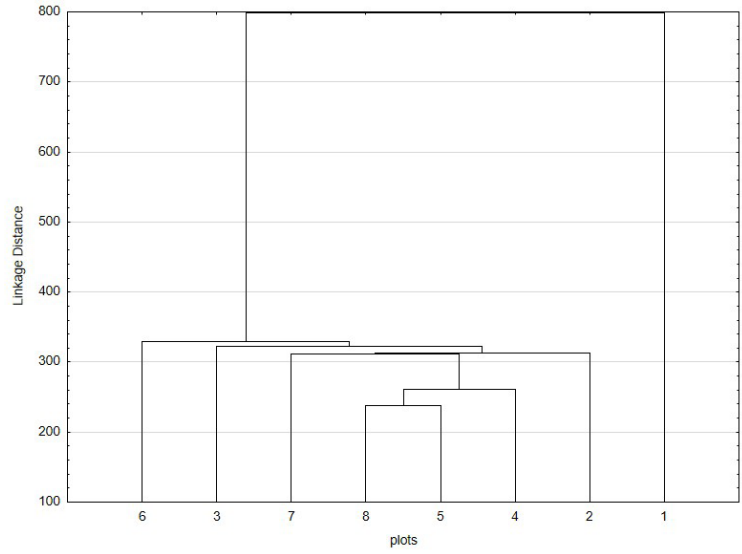

Fig. 6. Grouping of the obtained magnetic susceptibility values by sampling sites 
were quite differentiated in various seasons of the year; the highest values were recorded in summer, which makes this season most suitable for monitoring studies.

3. The decisive factors for magnetic susceptibility values were mainly the road surface condition, the construction material as well as the quantity and quality of communication and industrial pollution, emitted along the roads to soils.

4. The applied measurement of magnetic susceptibility is a good and reliable parameter, used in the studies of soil processes in urbanised areas.

\section{REFERENCES}

1. Bartington Instruments Ltd. 1999. Environmental Magnetic Susceptibility. Using the Bartington MS2 System - John Dearing. Oxford OX28 4GE, England, OM0409, 8.

2. Beckwith R., Ellis B., Revitt M., Oldfield F. 1986. Heavy metal and magnetic relationships for urban source sediments. Phys. Earth Planet Interiors, 42, 67-75.

3. Bućko M., Magiera T., Pesonen L., Janus B. 2010. Magnetic, geochemical, and microstructural characteristics of road dust on roadsides with different traffic volumes-case study from Finland. Wat. Air Soil Pollut., 209, 295-306.

4. Czerniak A, Poszyler-Adamska A. 2009. Road transportation impact on the soil environment trace metals migration range assessed by magnetic survey of soil. Infrastructure and ecology of rural areas, 5, 7-18.

5. Czerniak A. 2004. The influence of the cementground road fundations on the content of heavy metals in the assimilatory organs of the trees growing in the ecotone forest area. Pol. J. Environ. Stud., 13/III, 22-25.

6. Dearing J.A. 1999. Environmental magnetic susceptibility using the Bartington MS2 system. Chi, Kenilworth.

7. Evans E., Heller F. 2003. Environmental Magnetism. Academic Press Elsevier Science.

8. Gołuchowska B., Kusza G. 2010. Lime dusts as a source of environmental pollution in Opole Province. Proceedings of ECOpole, 4(1), 43-47.

9. Gołuchowska B., Strzyszcz Z., Kusza G. 2012. Magnetic susceptibility and heavy metal content in dust from the lime plant and the cement plant in Opole Voivodeship. Arch. Environ. Protect., 38(2), 71-80.

10. Hoffmann V., Knab M., Appel E. 1999.Magnetic susceptibility mapping of roadside pollution. J. Geochem. Explor., 66(9), 313-326.

11. Hunt A., Jones J. M., Oldfield F. 1984. Magnetic measurements and heavy metals in atmospheric particulates of anthropogenic origin. Sci. Total. Environ., 33, 129-139.
12. Łukasik A., Rachwał M., Strzyszcz Z. 2012. Application of magnetic susceptibility of soils for identification of potential sources of secondary dust emission in urban parks. Soil Sci. Ann., 63(4), 34-40.

13. Magiera T., Jabłońska M., Strzyszcz Z., Rachwał M. Morphological and mineralogical forms of technogenic magnetic particles in industrial dusts. Atmos. Environ., 2011, 45, 4281-4290.

14. Magiera T., Parzentny H., Lukasik A. 2016. The influence of the wind direction and plants on the variability of topsoil magnetic susceptibility in industrial and urban areas of southern Poland. Environ. Earth Sci., 75, 213.

15. Maher B.A. 1986. Characterisation of soils by mineral magnetic measurements. Phys. Earth. Planet Interiors, 42, 76-92.

16. Maher, B.A., Alekseev, A. Alekseeva, T. 2003. Magnetic mineralogy of soils across the Russian Steppe: climatic dependence of pedogenic magnetite formation. Paleogeog. Paleoclim. Paleoecol., 201, 321-341.

17. O Dell Statistica v. 13.1. 2016. Dell Inc.

18. Oldfield F. 1991. Environmental magnetism - a personal perspective. Quat. Sci. Rev. 10, 73-85.

19. Rachwał M., Kardel K., Magiera T., Bens O. 2017. Application of magnetic susceptibility in assessment of heavy metal contamination of Saxonian soil (Germany) caused by industrial dust deposition. Geoderma, 295, 10-21.

20. Schmidt A., Yarnold R., Hill M., Ashmore M. 2005. Magnetic susceptibility as proxy for heavy metal pollution: a site study. J Geoch. Explor., 85, 109-117.

21. Strzyszcz Z., Magiera T. 1998. Magnetic Susceptibility and Heavy Metal Contamination in Soils of Southern Poland. Phys. Chem. Earth, 23(9-10), 1127-1131.

22. Strzyszcz Z., Magiera T., Bzowski Z. 1994. Magnetic susceptibility as an indicator of soils contamination in some regions of Poland. Soil Sci. Ann., XLIV, 85-93.

23. Strzyszcz Z., Magiera T., Heller F. 1996. The Influence of Industrial Imissions on the Magnetic Susceptibility of Soils in Upper Silesia. Stud. Geophys. Geod., 40, 276-286.

24. Strzyszcz Z., Magiera T., Rachwał M. 2006. Application of soil magnetometry for identification of technogenic anomalies in trace metal and iron contents: a case study in the Katowice Forest District. Pol. J. Environ. Stud., 15(2a), 176-184.

25. Thompson R., Oldfield F. 1986. Environmental Magnetism. London: Allen \& Unwin, pp. 277.

26. Wawer M., Magiera T., Ojha G., Appel E., Bućko M., Kusza G. 2015a. Characteristics of current roadside pollution Rusing test-monitoring plots. Sci. Tot. Environ. 505, 795-804.

27. Wawer M., Magiera T., Ojha G., Appel E., Kusza G., Hu S., Basavaiah N. 2015b. Traffic-related pollutants in roadside soils of different countries in Europe and Asia, Wat. Air Soil Pollut., 226: 216. 